Article

\title{
In Situ Studies on the Characteristics of Strata Structures and Behaviors in Mining of a Thick Coal Seam with Hard Roofs
}

\author{
Yiwen Lan ${ }^{1,2}$, Rui Gao ${ }^{3, *}$, Bin Yu ${ }^{1,2}$ and Xiangbin Meng ${ }^{2}$ \\ 1 Key Laboratory of Deep Coal Resource Mining, School of Mines, Ministry of Education of China, China \\ University of Mining and Technology, Xuzhou 221116, China; db15020012b4cx@cumt.edu.cn (Y.L.); \\ yubin0352@163.com (B.Y.) \\ 2 Datong Coal Mine Group Co. Ltd., Datong 037000, China; mxb19818@126.com \\ 3 College of Mining Engineering, Taiyuan University of Technology, Shanxi 030024, China \\ * Correspondence: cumtgaorui@163.com; Tel.: +86-138-1346-4961
}

Received: 2 August 2018; Accepted: 12 September 2018; Published: 17 September 2018

\begin{abstract}
The movements of overburden induced by mining a thick coal seam with a hard roof extend widely. The effects of breakages in the hard strata on the strata behaviors might vary with the overlying strata layers. For this reason, we applied a test method that integrated a borehole TV tester, borehole-based monitoring of strata movement, and monitoring of support resistance for an in situ investigation of a super-thick, $14-20 \mathrm{~m}$ coal seam mining in the Datong mining area in China. The results showed that the range of the overburden movement was significantly high, which could reach to more than $300 \mathrm{~m}$. The key strata (KS) in the lower layer main roof were broken into a 'cantilever beam and voussoir beam' structure. This structure accounted for the 'long duration and short duration' strata behaviors in the working face. On the other hand, the hard KS in the upper layer broke into a 'high layer structure'. The structural instability induced intensive and wide-ranging strata behaviors that lasted for a long time (two to three days). Support in the working face were over-pressured by large dynamic factors and were widely crushed, while the roadways were violently deformed. Hence, the structure of a thick coal seam with a hard roof after mining will form a 'cantilever beam and voussoir beam and high layer structure', which is unique to a large space stope.
\end{abstract}

Keywords: in situ investigation; thick coal seam; strata behaviors; structural characteristics; longwall top coal caving (LTCC)

\section{Introduction}

The movement and control of the hard roof of a coal seam have always been key issues in coal mining. Strata behaviors and the control of strata behaviors are closely related to strata movement. At present, studies regarding strata behavior are more focused on the instability of broken strata within the near field main roof, and on how such instability affects the strata behavior. For example, Qian's theory of voussoir beams [1], and Song's theory of transferring rock beams [2], perfectly demonstrate strata breakages in the main roof and their effects on strata behaviors. These theories can serve as guides for understanding the schema and the control of strata behavior in the mining of thin or medium-to-thick coal seams, as, under such conditions, the mining thickness is small enough that the movements of overburden fall within a relatively small range after mining.

Thick coal seams are commonly found in Shanxi, Shaanxi, Xinjiang, and inner Mongolia in China. With the rapid application of mechanized mining techniques, thick coal seam mining nowadays mainly relies on top coal caving. Because of its high efficiency and rich production, thick coal seams have 
become the most productive and most important mining seams in China (See Figure 1). However, in the mining process, the thick coal seams tend to induce wide-reaching strata movements, complex stress distributions, and intensive strata behaviors in the working face. This is particularly so when the coal seam is covered by an overlying hard roof that breaks during mining. The long breakages, that is, the long weighting steps, and their far-reaching effects intensify the strata behaviors in the working face. Production practices have observed frequent strong strata behaviors of the working face after mining a thick coal seam with hard roof [3-6]. The roadways have been found to deform to the extent that they can no longer host the supports. Thus, the study of thick coal seam mining should not be confined to the effects of the lower layer strata in the main roof on strata behaviors. Attention should also be given to the significant effects of the broken and instable upper layer strata on strata behaviors.

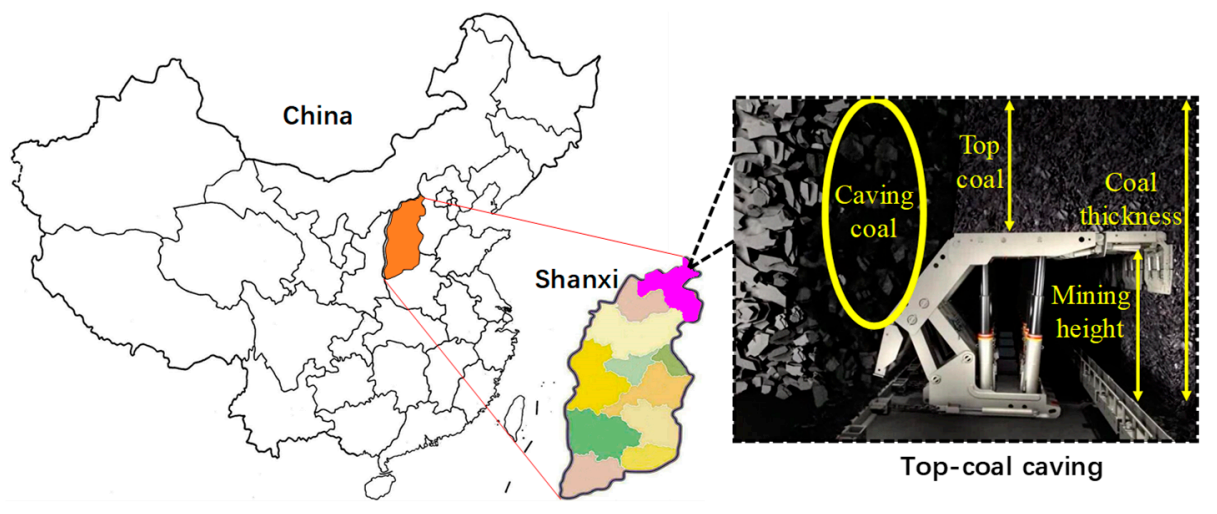

Figure 1. Mining overview of thick coal seam.

Much attention has been given to the characteristics of strata breakages both in and outside of China. Ju et al. [7] analyzed the structural characteristics of key strata (KS) and strata behavior in a 7-m-thick coal seam. Wang et al. [8] employed physical simulations to study the overburden fracture as well as the long duration and short duration strata behaviors in the working face of a shallow thick coal seam. Li et al. [9] studied the strata behaviors and forms of the broken roof in the working face of a thick coal seam. Yasitli NE et al. [10] analyzed the overburden fractures in the working face for a longwall top coal caving (LTCC) operation via numerical simulation. Alehossein $\mathrm{H}$ et al. [11] determined the stress distribution in the overlying rock of the working face for a top coal caving operation. Zhang et al. [12] combined a theoretical analysis with in situ investigations to discern the fracture heights of overburden in the working face of a thick coal seam. Other scholars [13-15] also conducted studies of a similar nature. However, these studies were rarely concerned with how the instabilities of the upper layer hard strata affected the strata behaviors in the working face. Previously, we [16,17] employed a micro-seismic monitoring and borehole TV tester to investigate the characteristics of the vertical and horizontal fractures induced from mining a thick coal seam. We found that the movements of overburden were far-reaching and complex after mining. Based on this study, we defined the large stope space and divided it into a far field and a near field [18]. However, our study lacked a systematic approach for measuring how the layer-based strata breakages in both the near and far fields affect strata behaviors.

In this study, we conducted field tests while mining a 14-20 m thick coal seam with hard roof in Datong, China (see Figure 1). An integrated method that included a borehole TV tester, borehole-based monitoring of strata movements, and monitoring of support resistance in the working face was employed. The fracture characteristics of the overlying rock layers and the strata behaviors were analyzed. The effects of strata breakages in the upper and lower layer strata on strata behaviors were derived.

\section{Experimental Design}

The site for engineering and tests was located in Tongxin Mine, Datong, China. The $200 \mathrm{~m}$ working faces were located in the No. 3-5 thick coal seams, whose thicknesses amounted to $16 \mathrm{~m}$. 
The overburden mainly consisted of sandstone, where the compressive strength ranged from $55.20 \mathrm{MPa}$ to $65.63 \mathrm{MPa}$, and the support resistance was $15,000 \mathrm{kN}$.

Two vertical boreholes, that is, the No. 1 and No. 2 boreholes, were drilled along the advancement direction of the working face to a depth of $474 \mathrm{~m}$, where the extracted coal seam was found. A strata movement monitor and a panoramic camera were installed in the No. 1 and No. 2 boreholes, respectively, to record the fractures and sinking of the overburden in real-time. The resistances in the supports of the working face were obtained at the same time for comparison with the measured data. Figure 2 illustrates the monitoring design.

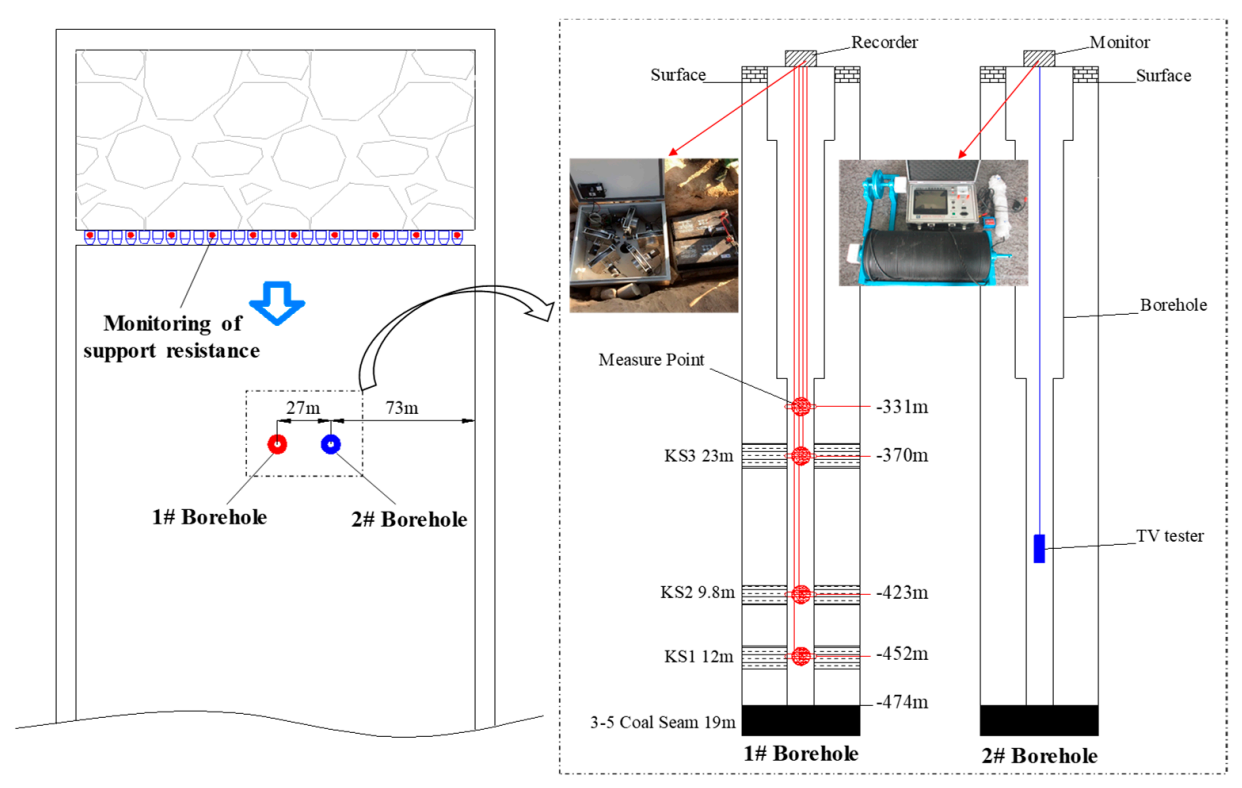

Figure 2. Measurement point layout and schema of monitoring apparatus.

(1) Monitoring of support resistance

Twelve supports for the working face were chosen for the resistance monitoring. These included support No.'s 5, 15, 25, 35, 45, 55, 65, 75, 85, 95, 105, and 115.

(2) Monitoring of key block movement

The KS position theory for strata control states that the strata behaviors are mainly subjected to breakages in the KS $[19,20]$. Based on this theory and the geological occurrences in the test field, we placed four measurement points in borehole No. 1. Measurement point Nos 1, 2, and 3 were located in the overlying KS, while No. 4 was located above the upper-most key block. The depths between the surface and the measurement points were $-452 \mathrm{~m},-423 \mathrm{~m},-370 \mathrm{~m}$, and $-331 \mathrm{~m}$, organized from measurement points No. 1 to No. 4. As shown in Figure 2, the thickness of KS1, KS2, and KS3 was $12 \mathrm{~m}, 9.8 \mathrm{~m}$, and $23 \mathrm{~m}$, and all of the strata consist of sandstones.

Each measurement point was bound with the corresponding KS, using a claw structure to ensure synchronized movement. The claw structure was pulled through to the work station on the surface by a steel wire rope for recording purposes. In the process of installation, the claw structure was firstly placed in the position of KS, and then the claw was flicked and fixed on the KS. The claw structure moved in step with the KS, and the movement data was recorded by the steel wire rope, which was connect to a counter in the surface. The data accuracy was $1 \mathrm{~mm}$, and the data were installed in a memory card. The one motion range of the steel wire rope and claw structure could reach $20 \mathrm{~m}$, which could fully meet the monitoring requirements of thick coal seam mining.

Placing the measurement points in the KS was an effective countermeasure for the wire rope winding problem in a blinding layout. 
(3) Monitoring of overburden failure

Applying a borehole TV tester to the monitoring was beneficial for obtaining an intuitive understanding of the overburden fractures. The borehole TV tester was equipped with a 15 in SONY professional LCD display, a zoomable lens, and a 120 million static pixels SONY high-speed camera. Professional waterproof underground cables capable of withstanding a maximum tension of $200 \mathrm{kgf}$ were used. The borehole TV tester was expected to monitor the working face for three months at a consecutive advancing distance of $400 \mathrm{~m}$. Table 1 lists the plan for monitoring, while Figure 2 provides an overview of the measure point layout in the working face.

Table 1. Borehole monitoring plans.

\begin{tabular}{cc}
\hline Relative Position of the Borehole to the Working Face & Monitoring Plan \\
\hline $200-0 \mathrm{~m}$ & Once every five days \\
$200-50 \mathrm{~m}$ & Once every three days \\
$20-0 \mathrm{~m}$ & Once every two days \\
$0--50 \mathrm{~m}$ & Once every two days \\
$-50--200 \mathrm{~m}$ & Once every three days \\
\hline
\end{tabular}

\section{Results and Analysis}

\subsection{Characteristics of Overburden Fracture}

As the working face advanced, the broken strata began to sink and the four measurement points in borehole No. 1 sank with the strata. Figure 3 presents the movement process of the overlying strata measured at the four measurement points.

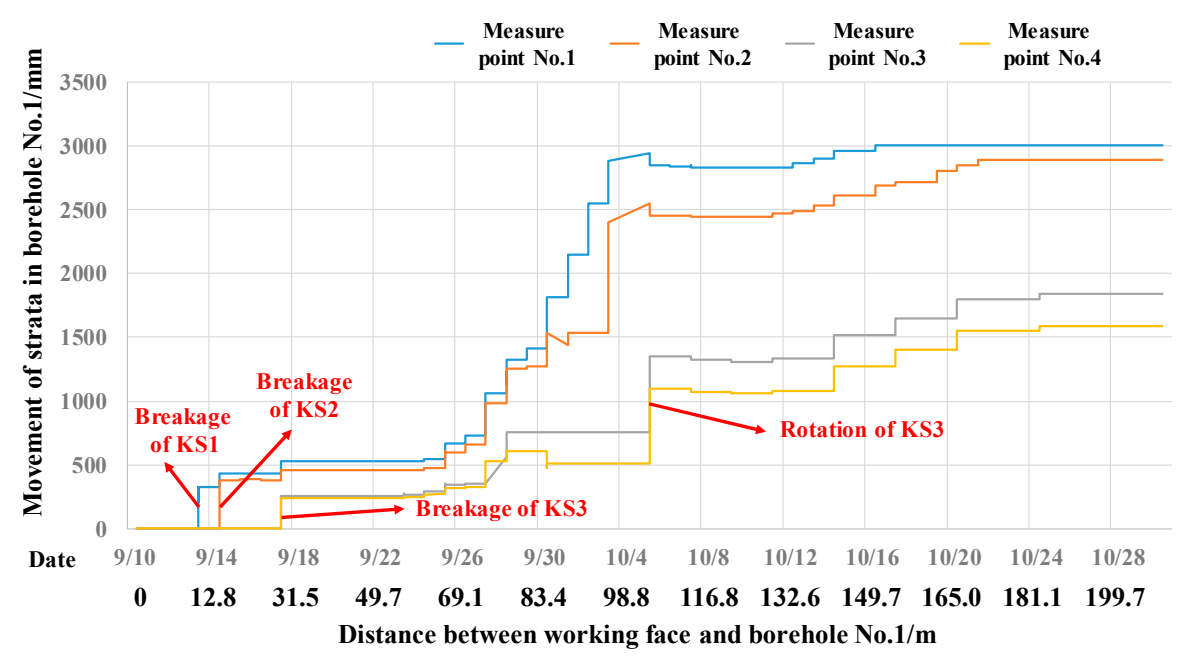

Figure 3. Variation of strata movement in borehole No. 1 with advancement of the working face.

As shown in Figure 3, the movement of the strata showed the following characteristics:

(1) On the whole, there was a 'stepped hopping-smooth' variation in the movement, until the strata stabilized.

(2) When the working face was advanced over the borehole by $10.8 \mathrm{~m}$, the measurement point No. 1 sank by $306 \mathrm{~mm}$. This implies that KS1 had broken. When the working face further advanced over the borehole by $14.5 \mathrm{~m}$, the measurement point No. 2 sank by $382 \mathrm{~mm}$. This implies that KS2 had broken, which in turn induced the first stratum to sink another $84 \mathrm{~mm}$. This was expressed as a second sinking in measurement point No. 1. When the working face advanced to $98 \mathrm{~m}$ away from the borehole, the movement data in No. 1 and No. 2 stabilized. This meant that the broken strata below a depth of $-423 \mathrm{~m}$ had fully caved in. 
(3) The change in data of the measurement points No. 3 and No. 4 showed a consistent trend, which implies that the breakages in KS3 was important to the movement of its overlying rock strata. When the working face advanced over the borehole by $31.5 \mathrm{~m}, \mathrm{KS} 3$ at a higher position broke for the first time, but the rotation was within a very small range. Measurement point No. 3 only sank by $218 \mathrm{~mm}$. As the working face advanced to $98.8 \mathrm{~m}$ ahead of the borehole, No. 3 and No. 4 continued to sink, where the movement of No. 3 increased from $750 \mathrm{~m}$ to $1350 \mathrm{~m}$. From 4 October to 16 October, the data measured in No. 1 and No. 2 increased slightly. This means that rotation in KS3 affected KS1 and KS2 by compacting the collapsed rocks. When the working face advanced to $180 \mathrm{~m}$ ahead of the borehole, all of the movements in all of the KS had stabilized.

\subsection{Analysis of Strata Behaviors}

Figure 4 denotes the fracture height curve recorded by the borehole TV tester. The curve ascends in a stepped jump manner and the maximum fracture height approaches $320 \mathrm{~m}$. This further proves that KS1, KS2, and KS3, which were being monitored, broke. It can be inferred from Figure 3 that the stratum broke whenever the measured movement data rose. Hence, the effects of strata movement on strata behaviors can be achieved by analyzing the support resistances obtained at the points when the data from Figures 3 and 4 increased. The resistances of support No. 55 in the very middle of the working face were obtained at each point along the 'Breakage of the $\mathrm{KS1}^{\prime}$, 'Breakage of the $\mathrm{KS2}^{\prime}$ ', and 'Rotation of the KS3' in Figure 3, where the measured data changed. A comprehensive analysis was then conducted using the obtained resistances to investigate how the breakage and rotation in strata at lower and higher positions affect the strata behaviors in the working face.

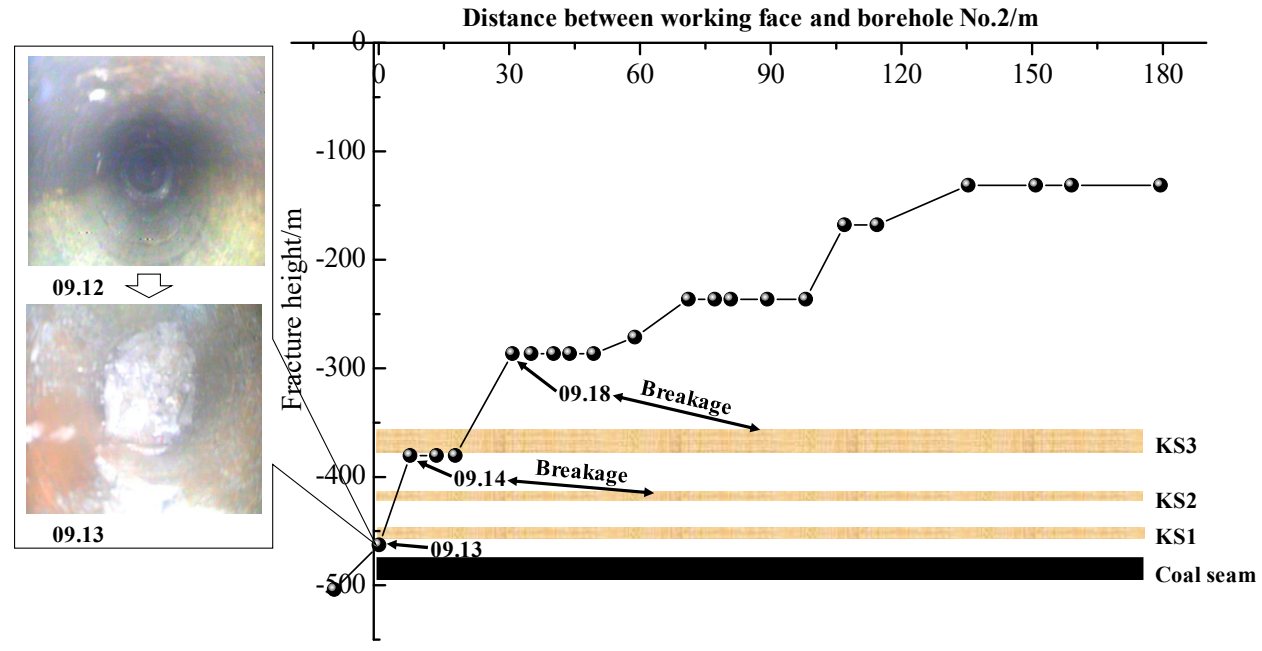

Figure 4. Fracture height curve recorded by the borehole TV tester.

(1) Breakages in the KS1 and KS2

The displacement data of measurement point No. 1 showed an increase on 13 September. This data was combined with the borehole TV tester monitoring data on 12 and 13 September, which showed that the borehole was fully unblocked on 12 September, but was blocked by overlying strata at a depth of $-450 \mathrm{~m}$ on 13 September (Figure 4). This showed that KS1 was broken. The resistance of support No. 55 at this point increased, as shown in Figure 5, thereby reflecting the strata behaviors in the working face for a short time. This behavior lasted for $7 \mathrm{~h}$, and the average dynamic factor of the support was 1.15.

The data of measurement point No. 2 began to rise after 14 September. The borehole TV tester showed that the fracture height at this point developed to $-370 \mathrm{~m}$ (See Figure 4), implying that KS2 broke. The resistance of support No. 55 obtained at this point also increased (See Figure 5). Comparing the strata behaviors induced by the broken KS1, the strata behaviors were so dramatic that 
the safety valves at the No. 49 to No. 79 supports were forced open. These behaviors lasted for $16 \mathrm{~h}$, and the average load factor was 1.34 .

As can be seen in Figure 5, the support working resistance had already increased before the KS broke, because of the concentrated rock stress. The strata rotated and sank after the breakage, thus, the support working resistance remained high for a certain range of time.

(2) Rotation in KS3 at a higher position

As can be seen from Figure 3, the data measured at measurement points No. 1 and No. 2 continued to increase from 28 September to 5 October. This means that KS1 and KS2 were continuously, but slowly rotating. Meanwhile, the data measured at No. 3 and No. 4 remained stable, indicating that KS3 at a higher position was in a stable state and was not rotating. The separation between KS3 and the strata beneath grew larger and larger until 5 October, when KS3 lost stability and underwent a substantial rotation. The resistances recorded at this moment showed that the working face was experiencing strata behavior (Figure 6). Comparing the strata behaviors induced by the broken KS1 and KS2, the strata behaviors lasted for the longest time of $43 \mathrm{~h}$. The No. 35 to No. 95 supports were crushed under the force (Figure 7). The average dynamic factor reached 1.54.

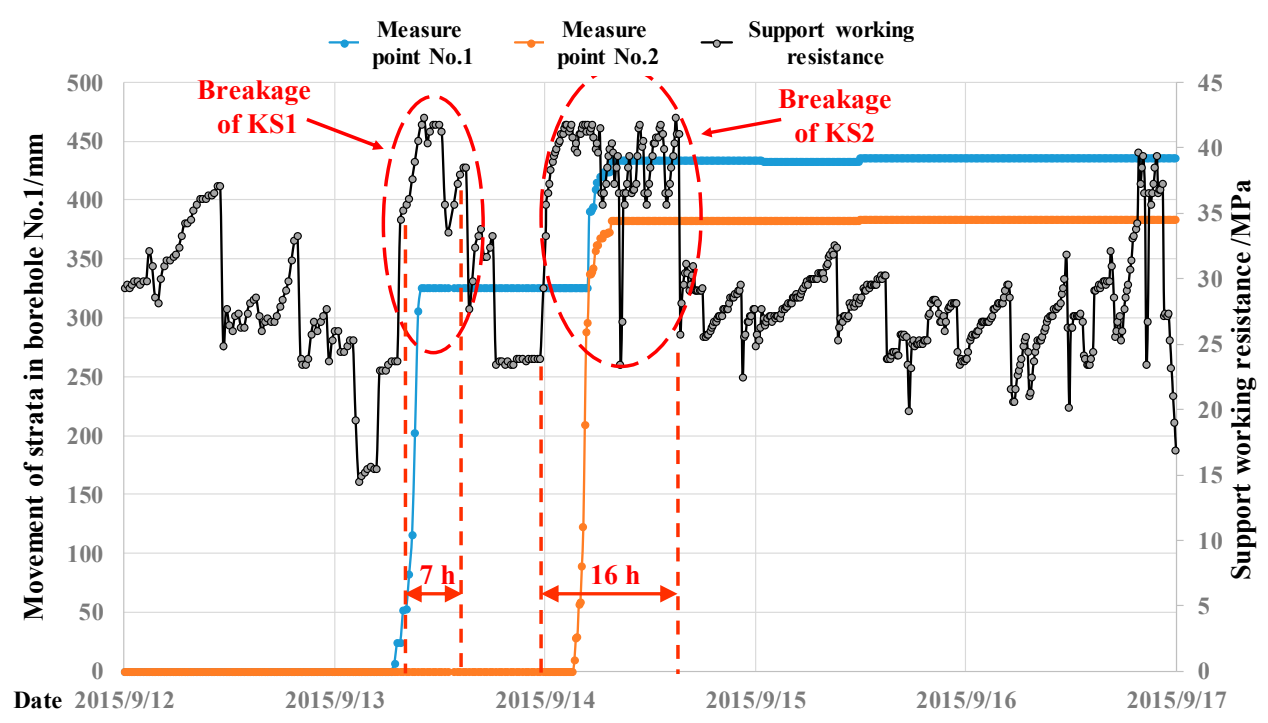

Figure 5. Resistances in No. 55 support along the breakages of key strata KS1 and KS2.

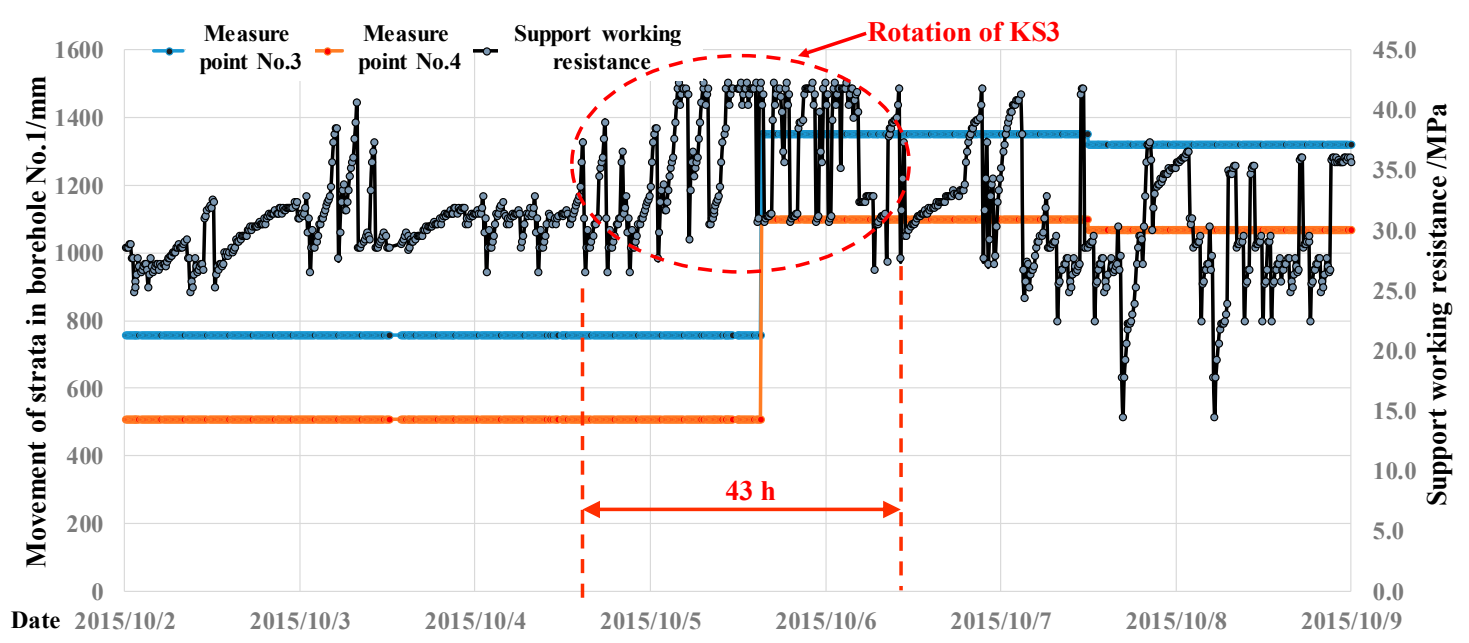

Figure 6. Resistances in No. 55 support along the rotations of KS3. 


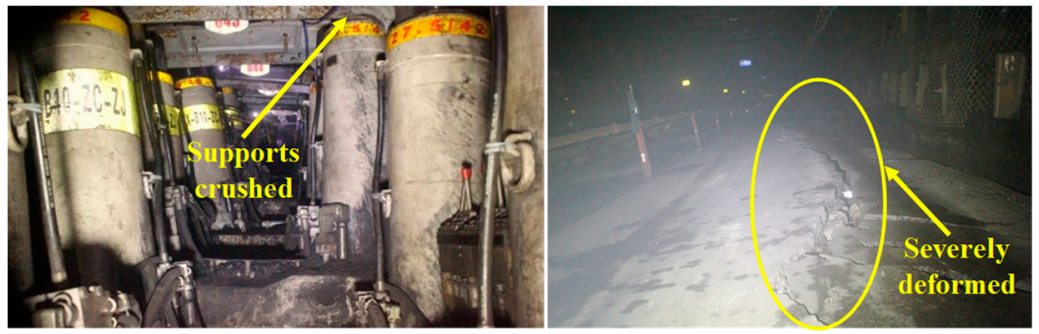

Figure 7. Roadway deformation.

Meanwhile, the monitor found that when KS3 broke, a range of $150 \mathrm{~m}$ ahead of the roadway for the working face was severely deformed. The roadway roof shifted over a length of $1.5 \mathrm{~m}$ (the roadway was $3 \mathrm{~m}$ high). The roadway bedding was found to be violently protruding, while the supports $80 \mathrm{~m}$ ahead of the working face were badly damaged, as shown in Figure 7.

\section{Discussion}

A statistical analysis was conducted to analyze the variation of the support resistance with the advancement in the working face (Figure 8). The results showed 'long duration and short duration' strata behaviors in the supports of the working face. As can be seen from Figure 8, the strata behaviors at the breaking point of KS1 lasted for a 'short time', while those at the breaking point of KS2 lasted for a 'long time'. In the 'long duration' case, the strata behaviors were intensive, the supports were highly pressured, and the behaviors lasted for a relatively long time. The statistical results showed that in the 'short duration' case, the weighting steps of the strata behaviors ranged from $15 \mathrm{~m}$ to $25 \mathrm{~m}$, and had an average step of $18 \mathrm{~m}$. In the 'long duration' case, the weighting steps of the strata behaviors normally ranged from $30 \mathrm{~m}$ to $65 \mathrm{~m}$, and the average step was $40 \mathrm{~m}$ long.

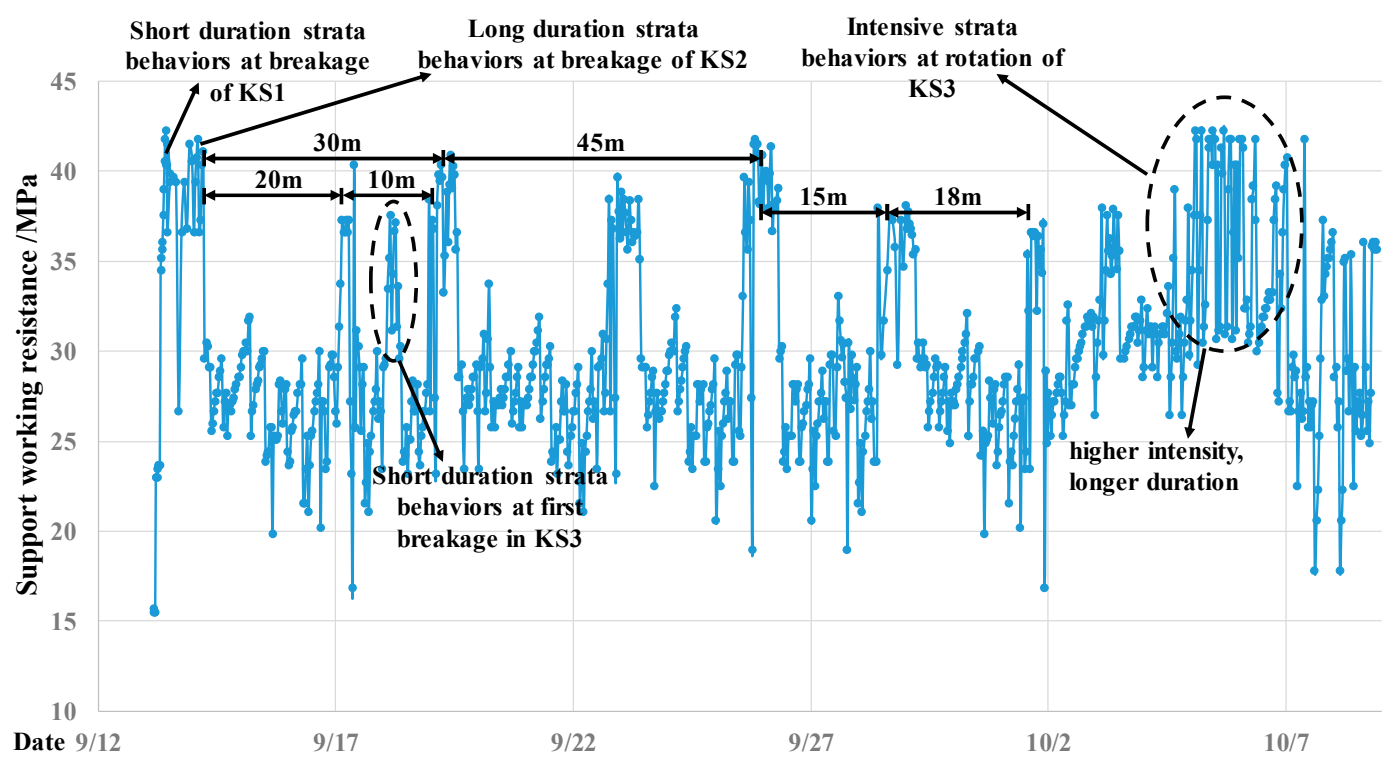

Figure 8. Strata behaviors on supports in the working face.

These cyclic characteristics of the strata behaviors are rooted in the 'cantilever beam and voussoir beam' $[4,8]$ structure of the strata in the main roof. The broken cantilever beam (formation of KS1) induced short strata behaviors, while the instability of the voussoir beam (formation of KS2) caused long strata behaviors in the working face.

As can be seen from Figures 3 and 8, on 18 September, the KS3 sank by $218 \mathrm{~mm}$ upon the first breakage. Owing to the slight movement, breakages at this key block only caused a short period of 
strata behaviors. As seen in Figures 3, 6 and 8, on 5 October, a substantial rotation of $600 \mathrm{~mm}$ in KS3 induced intensive strata behaviors in the working face. Comparing the previous short duration of the strata behaviors in this stratum, this time, the behaviors forced some supports to crush and lasted for a long time. It is evident that when the rotation was substantial, the key block tended to lose stability and easily induced intensive strata behaviors in the working face. At this point, the rotation lagged $109 \mathrm{~m}$ behind the working face. From this, we determined that the instability in a key block at a higher position was the major factor that induced strong strata behaviors. However, no significant regularity was observed for the weighting steps in this stratum, that is, the weighting steps for intensive strata behaviors in the working face. We concluded from the analysis that the complex movements caused the stratum to lose stability, and that the rotations of the unstable stratum in turn exerted significant effects on the strata behavior intensity.

To further study the overburden fracture characteristics for differing coal seam thickness, we also performed field tests in the No. 8108 working face of the Tashan Mine adjacent to the Tongxin Mine. The average thickness of the coal seam in this working face was $21.22 \mathrm{~m}$. The working face was located at a depth of 418-522 $\mathrm{m}$ and the longwall panel was about $1500 \mathrm{~m}$ long and $230 \mathrm{~m}$ wide. Four KS, that is, KS1, KS2, KS3, and KS4, in four different layers were chosen as the study objects. A curve of the caved height, as shown in Figure 9, was obtained by combining the borehole TV tester monitoring and the working face strata behavior analysis to test the overburden fracture.

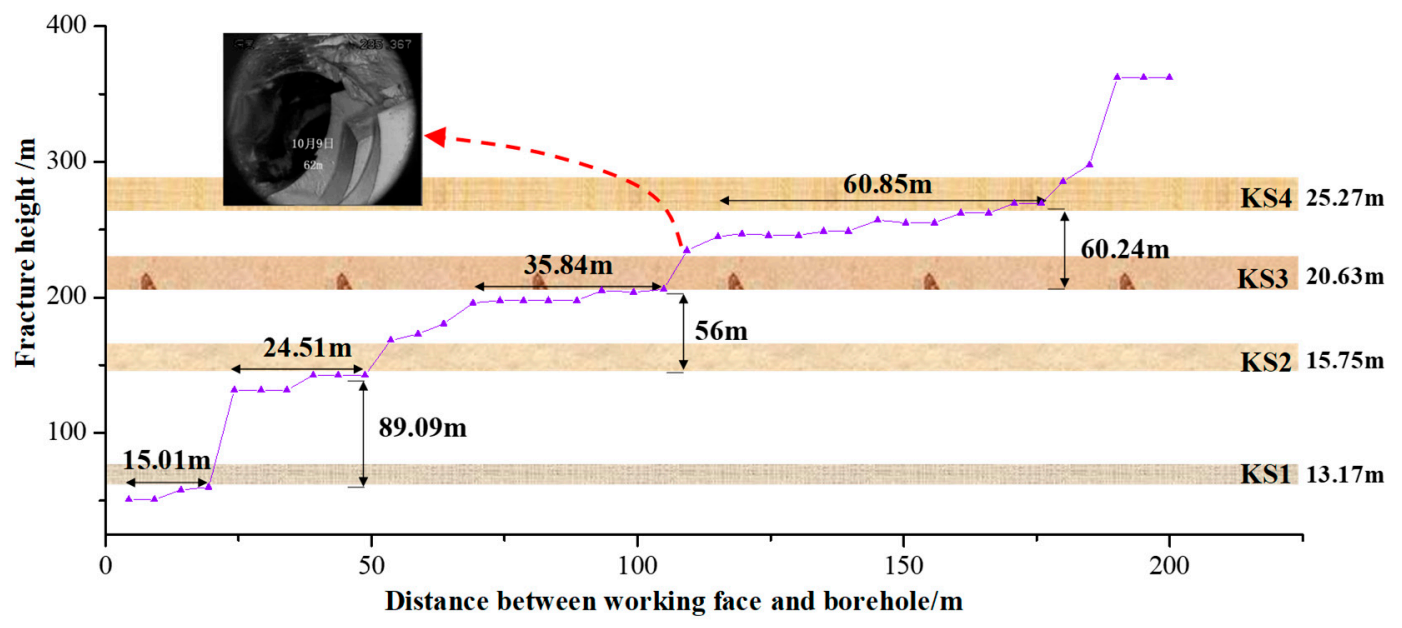

Figure 9. Fracture height curve.

As shown in Figure 9, as the working face advances, the caved height is closely related to the key block occurrences. The caved height increased each time the key block broke. The maximum caved height reached $350 \mathrm{~m}$. From the curve, we can see that the length of each plateau was associated with the weighting step of each stratum, which increased with the height of the layer. In KS1, the weighting step was $21.02 \mathrm{~m}$ long, while that of KS4 was $175 \mathrm{~m}$ long. In situ measurements showed that the strata behaviors at the breaking point of KS4 were intensive, which forced the supports to collapse and the roadways to deform. In the working face, the behaviors lasted for two to three days. Compared with the results obtained in the Tongxin Mine, we found that the caved heights increased with the increasing mining thickness in the coal seam.

Summarizing the field measurements from both the Tongxin Mine and the Tashan Mine, the following findings were observed: the broken KS in the lower layers, for example, KS1 and KS2, formed a structure of 'cantilever beam and voussoir beam'. These 'long duration and short duration' strata behaviors were induced in the working face. The vertical distances from the key block to the coal seam at this point were typically short. In the cases of the Tongxin Mine and the Tashan Mine, the ratio of the distance from the key block to the coal seam to the mining thickness in the working face was lower than 3.19. However, when the upper layer key hard strata (for example, KS3 and KS4) 
were broken, a 'high layer structure' was sometimes formed. The weighting step in this structure was long. Although rotation occurred when the structure lost stability at $109 \mathrm{~m}$ (Tongxin Mine) and $175 \mathrm{~m}$ (Tashan Mine) behind the working faces, respectively, this instability still exerted a great influence on the strata behaviors in the working faces. More specifically, the strata behaviors were intensive and their effects extended to a wide range. At this point, the ratio between the distance from the key block to the coal seam and the working face mining thickness was 6.5. Based on this analysis, we can summarize the strata structure characteristics and strata behaviors after mining a thick coal seam with hard roof, as shown in Figure 10.

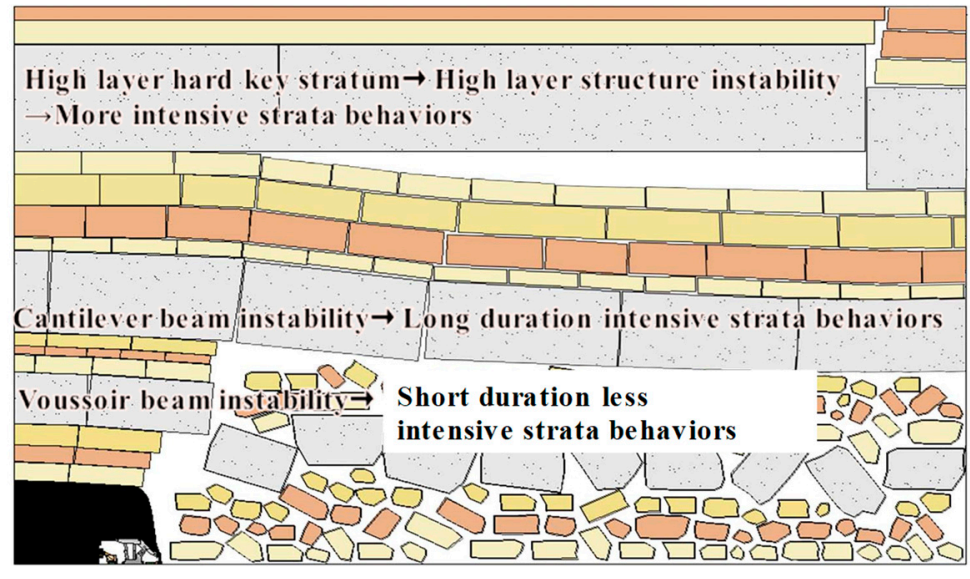

Figure 10. Strata structure and strata behavior characteristics.

\section{Conclusions}

(1) Engineering practices showed that the maximum fracture heights at the Tongxin Mine and the Tashan Mine were $320 \mathrm{~m}$ and $350 \mathrm{~m}$, respectively. The fracture heights and weighting steps of the collapsed KS increased with the increasing thickness of the coal seam being mined.

(2) In situ investigations found that the cantilever beam structure and voussoir beam structure were easily formed when the KS of the lower layer main roof was broken. In the cantilever beam structure, the short duration strata behaviors in the working face were induced. The length of the weighting steps varied from $15 \mathrm{~m}$ to $25 \mathrm{~m}$, while the average length was $18 \mathrm{~m}$. When the voussoir beam structure lost its stability, long duration strata behaviors were induced. The weighting steps were 30-65 m long, while the average weighting step was $40 \mathrm{~m}$.

(3) When mining the thick coal seams with hard roofs, even when the high layer structures lost stability at $109 \mathrm{~m}$ (Tongxin Mine) and $175 \mathrm{~m}$ (Tashan Mine), far behind the working face, intensive strata behaviors were induced. The behaviors lasted for two to three days, which caused severe damage to the supports. Hence, instability movements in the high layer KS can be deemed as the principal factor inducing strata behaviors in the working face.

(4) Field measurements showed that a complex and systematic 'cantilever beam and voussoir beam and high layer' structure was formed in the large stope space. When the structure lost its stability, the induced strata behaviors demonstrated complex 'long duration and short duration and high intensity' characteristics.

(5) This paper applied field tests to obtain the strata structure and strata behaviors for the mining of a thick coal seam with hard roof. The existence of a 'high layer structure' was proven, and its effects on the strong strata behaviors were demonstrated. However, further investigations are required to study the formation and stability loss processes, especially the effects of the structure on the strata behaviors in roadways ahead of the working face.

Author Contributions: Y.L. designed and implemented the scheme of field experiment; R.G. and B.Y. analyzed the data and wrote the paper; X.M. collected the practical data. 
Funding: This research was funded by the Special Funding Projects of 'Sanjin Scholars' Supporting Plan, grant number [2050205], the State Key Research Development Program of China, grant number [2016YFC0600701], and the State Key Research Development Program of China, grant number [2018YFC0604506].

Acknowledgments: We are also grateful to Zhu Weibing, Li Zhu in China University of Mining and Technology for their assistance in field tests.

Conflicts of Interest: The authors declare no conflict of interest.

\section{References}

1. Qian, M.G.; Miao, X.X.; He, F.L. Key block analysis of voussoir beam structure in the stope. J. China Coal Soc. 1994, 19, 557-563.

2. Lu, G.Z.; Tang, J.Q.; Song, Z.Q. Difference between cyclic fracturing and cyclic weighting interval of transferring rock beams. Chin. J. Geotech. Eng. 2010, 32, 538-541.

3. Bai, Q.S.; Tu, S.H.; Wang, F.T.; Zhang, C. Field and numerical investigations of gateroad system failure induced by hard roofs in a longwall top coal caving face. Int. J. Coal Geol. 2017, 173, 176-199. [CrossRef]

4. Zheng, Z.T.; Xu, Y.; Li, D.S.; Dong, J.H. Numerical Analysis and Experimental Study of Hard Roofs in Fully Mechanized Mining Faces under Sleeve Fracturing. Minerals 2015, 5, 758-777. [CrossRef]

5. Tan, Y.L.; Zhao, T.B.; Xiao, Y.X. Quantitative prop support estimation and remote monitor early warning for hard roof weighting at the Muchengjian Mine in China. Can. Geotech. J. 2010, 47, 947-954. [CrossRef]

6. Zhang, J.X.; Li, B.Y.; Zhou, N.; Zhang, Q. Application of solid backfilling to reduce hard-roof caving and longwall coal face burst potential. Int. J. Rock Mech. Min. Sci. 2016, 88, 197-205. [CrossRef]

7. Ju, J.F.; Xu, J.L. Structural characteristics of key strata and strata behavior of fully mechanized longwall face with 7.0 m height chocks. Int. J. Rock Mech. Min. Sci. 2013, 58, 46-54. [CrossRef]

8. Wang, G.; Luo, H.Z.; Wang, J.R.; Tian, F.C.; Wang, S. Broken laws of key strata on strata behaviors in large height fully-mechanized face of nearly shallow coal seam. J. China Univ. Min. Technol. 2016, 45, 469-474.

9. Li, H.M.; Jiang, D.J.; Li, D.Y. Analysis of ground pressure and roof movement in fully-mechanized top coal caving with large mining height in ultra-thick seam. J. China Coal. Soc. 2014, 39, 1956-1960.

10. Yasitli, N.E.; Unver, B. 3D numerical modeling of longwall mining with top-coal caving. Int. J. Rock Mech. Min. Sci. 2005, 42, 219-235. [CrossRef]

11. Alehossein, H.; Poulsen, B.A. Stress analysis of longwall top coal caving. Int. J. Rock Mech. Min. Sci. 2010, 47, 30-41. [CrossRef]

12. Zhang, H.W.; Zhu, Z.J.; Huo, L.J.; Chen, Y.; Huo, B.J. Overburden failure height of superhigh seam by fully mechanized caving method. J. China Coal Soc. 2014, 39, 816-821.

13. Cai, W.; Dou, L.M.; Gong, S.Y.; Li, Z.L.; Yuan, S.S. Quantitative analysis of seismic velocity tomography in rock burst hazard assessment. Nat. Hazards 2015, 75, 2453-2465. [CrossRef]

14. Palchik, V. Localization of mining-induced horizontal fractures along rock layer interfaces in overburden: field measurements and prediction. Environ. Geol. 2005, 48, 68-80. [CrossRef]

15. Unver, B.; Yasitili, N.E. Modelling of strata movement with a special reference to caving mechanism in thick seam coal mining. Int. J. Coal Geol. 2006, 66, 227-252. [CrossRef]

16. Yu, B.; Zhao, J.; Kuang, T.J.; Meng, X.B. In situ investigations into overburden failures of a super-thick coal seam for longwall top coal caving. Int. J. Rock Mech. Min. Sci. 2015, 78, 155-162. [CrossRef]

17. Yu, B.; Zhao, J.; Xiao, H.T. Case Study on Overburden Fracturing during Longwall Top Coal Caving Using Microseismic Monitoring. Rock Mech. Rock Eng. 2017, 50, 507-511. [CrossRef]

18. Yu, B.; Zhu, W.B.; Gao, R.; Liu, J.R. Strata structure and its effect mechanism of large space stope for fully-mechanized sublevel caving mining of extremely thick coal seam. J. China Coal Soc. 2016, 41, 572-581.

19. Miao, X.X.; Qian, M.G. Advance in key strata theory of mining rockmass. J. Min. Technol. 2000, 29, 25-29.

20. Qian, M.G.; Miao, X.X.; Xu, J.L. Theoretical study of key stratum in ground control. J. China Coal Soc. 1996, $21,225-230$. 